\title{
Indian husbands' support of their wives' upward mobility in corporate South Africa: Wives' perspectives
}

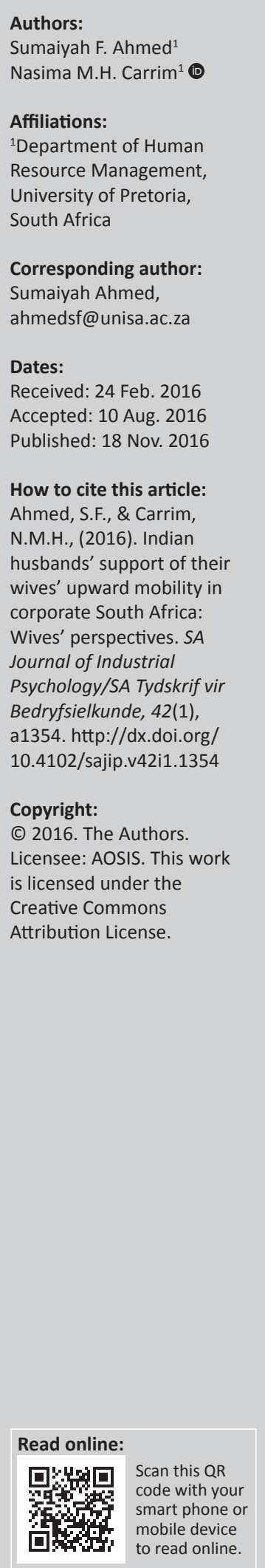

Orientation: Spousal support is a crucial area to explore, particularly due to the increased prevalence of dual-career couples in South Africa and the dynamics facing them.

Research purpose: The main objective of this study was to explore Indian wives' perceptions regarding the support they receive from their husbands and the impact that such support has on their career progression.

Motivation for the study: The limited qualitative research available globally on the subject and the dearth of research that focuses on Indian professional females in the South African context motivated the study.

Research design, approach and method: A qualitative research approach was followed, and the data were collected through in-depth, life-story interviews. Purposeful and snowball sampling methods yielded a sample of nine Indian female managers who were in dual-career marriages.

Main findings: Spouses are essential sources of support for Indian professional women. The findings revealed that there are various marital and socio-cultural dynamics that impact on the spousal support received by these women, which ultimately influences their career advancement.

Practical/managerial implications: The findings provided valuable information regarding the marital challenges that Indian women face in their career progression. The awareness of such dynamics can assist management in devising strategies to accommodate and retain the unique talent that Indian women have to offer.

Contribution/value-add: The study contributes to the evolving body of knowledge on dualcareer couples by focusing on an under-researched, but essential aspect of the dual-career arrangement.

\section{Introduction}

The career aspirations of women worldwide gave rise to the increasing prevalence of dual-career couples who are required to constantly navigate between their personal and professional lives (Abele \& Volmer, 2011; Tengimfene, 2009). Although there is a strong presence of women in various workplaces globally, with women at entry level being placed on an equal footing with men, there appears to be disparity with regard to their career advancement at higher management levels (Davidson \& Burke, 2012). A similar picture is painted in the South African context as women constitute only $20.9 \%$ of top management positions and $32.1 \%$ of senior management positions in the country (Department of Labour, 2015). Indian women possess the capabilities that drive success in organisations and are viewed as being amongst the most highly motivated and ambitious women in the world (Hewlett \& Rashid, 2011). However, South African Indian women occupy only $2.1 \%$ of top management positions and $3.2 \%$ of senior management positions in the country (Department of Labour, 2015).

In an attempt to understand why this underrepresentation occurs, researchers have focused on the organisational factors that obstruct the career advancement of women (Bilimoria, Joy \& Liang, 2008; Tlaiss \& Kauser, 2010). Factors external to the workplace, such as societal and familial expectations, as well as cultural and religious prescriptions have also been identified as barriers to the career advancement of women (Carrim, 2012, 2015; Rastogi \& Bansal, 2012). However, marital status has been acknowledged as a significant factor that impacts on a woman's career progression (Mavin, 2000). Specifically, researchers have found that job-spouse conflict often serves as a barrier to the career progression of women (Namayandeh, Yaacob \& Juhari, 2010; Wei, Ying \& Liangliang, 2009). It is therefore important that the impact of the spouse on a wife's career 
be examined as the husband is the closest person to a married employed woman and is regarded as the most significant source of social support for most adults (Dorio, 2009; Noor, 2002). Limited research has, however, been conducted on the impact of husbands' roles in their wives' career advancement, even though the husband has been identified as a vital role player in the career progression of women (Ezzedeen \& Ritchey, 2008). Globally, only a few studies could be found that focus specifically on spousal support amongst dualcareer couples (Ezzedeen \& Ritchey, 2008; Gordon \& WhelanBerry, 2004; Välimäki, Lämsä \& Hiillos, 2009). These studies are not without their limitations, as they were conducted in Western countries and the findings may not be completely interpretable in the South African context because of the diversity and uniqueness of the population.

The need for research that focuses specifically on the husband in a dual-career arrangement is intensified in the Indian context, as traditional Indian culture requires women to be devoted and subservient to their husbands (Rastogi \& Bansal, 2012). Even though Indian women are pursuing careers, they are not absolved of the traditional cultural expectations which are focused on women shouldering the domestic responsibilities (Carrim, 2015; Carrim \& Nkomo, 2016; Patel, Govender, Paruk \& Ramgoon, 2006). Thus, Indian professional women face difficulty in reconciling their traditional roles with that of contemporary professional women (Carrim, 2012). In addition, there is also a change in family structure of Indians as the traditional norm of joint or extended families are replaced by nuclear families that consist of the husband, wife and their unmarried children (Narayan \& Bhardwaj, 2005; Rastogi \& Bansal, 2012). This has caused a reduction in the social support offered to women and has placed greater importance on the husband's support (Narayan \& Bhardwaj, 2005). Furthermore, Indian women are required to be subservient and devoted to their spouses and are expected to put their own needs secondary to the needs of their families (Rastogi \& Bansal, 2012; Salway, Jesmin \& Rahman, 2005). Thus, it is no surprise that Indian women encounter unique obstacles in their climb up the corporate ladder (Carrim, 2012; Carrim \& Nkomo, 2016).

Earlier studies conducted in the South African context focused mainly on the experiences of white and black female managers in their career progression, while Indian females have been studied as a subcategory of black women and have not been examined exclusively (Booysen \& Nkomo, 2010; Carrim, 2012). Thus, we focus on the perspectives of South African Indian women executives regarding the support offered by their husbands and the impact it has on their career advancement. We also explore the cultural and marital factors that impact on the perceptions of spousal support received by the wives. This study provides valuable insight to corporate leaders and management consultants to aid in their diversity management initiatives and sensitise them to the dynamics that married Indian women face in their personal lives while progressing in their careers. We recognised the need for a study of such a nature to be conducted in the South African context, due to the distinct realities that exist and the limited research available on the subject.

The literature review in the following section analyses the theoretical framework on spousal support along with the socio-cultural dynamics that have impacted on the career progression of Indian women and spousal support amongst dual-career couples. The research methodology and results of the study are then presented and discussed. Finally, the conclusions, shortcomings of the research and recommendations for future research are discussed.

\section{Literature review}

\section{Theoretical framework and socio-cultural dynamics}

The main theoretical framework on which the study focused is spousal support theory. Kanter (1977) proposed the spousal support theory, which suggests that having a spouse provides supplementary resources required for career success. Thus, married men are able to offer greater resources to their professions than single men. Wives, particularly stay-athome wives, offer resources such as shouldering the domestic responsibilities, advising and assisting husbands with workrelated tasks, as well as providing time and drive for their husbands' undertakings (Reitman \& Schneer, 2008). Thus, this theory postulates that wives contribute positively to their husbands' career advancement.

Cohen, Granot-Shilovsky and Yishai (2007) highlighted that wives require greater spousal support for their career progression than their husbands. However, an ironical situation emerges as women may not receive such support because of: the imbalanced division of labour in the home domain (Gershuny \& Bittman, 2005), the husband's career taking precedence over the wife's career (Valcour \& Tolbert, 2003), the unlikelihood of a stay-at-home husband (Scheener \& Reitman, 2002) and women offering greater resources for their husbands' careers than the resources received for their careers (Beauregard, 2008). Thus, spousal support theory posits that married women will not advance to the same extent as single women as they will be less committed and attentive to their careers (Beauregard, 2008; Whiting, 2004). Spousal support theory was used in this study to establish whether marriage serves as an obstacle in the career advancement of Indian women.

The Indian culture has been classified as being collective in nature, wherein members of the group abide by the customs of the social group in order to be accepted (Carrim, 2012; Luk \& Schaffer, 2005). Indians are thus likely to conform to social norms as it provides them with a sense of security, belonging and control (Sonpar \& Kapur, 2001) and, as a result, social approval is of greater significance to Indians than individual achievement (Banerjee, 2008). Thus, there is a striking sociocultural influence on the behaviour and personality of Indian individuals (Shivani, Mukherjee \& Sharan, 2006). 
The traditions originating from India have impacted on South African Indian women with the culture prescribing women to be primarily responsible for domestic tasks and husbands to be the financial providers for the family (Patel et al., 2006; Salway et al., 2005). In addition, attending to family needs is the main concern for the majority of Indian females as the Indian culture views family as being central to a female's existence (Carrim, 2012; Rajadhyaksha \& Bhatnagar, 2000; Vangarajaloo, 2011). It has also been the norm for Indian families to be extended or joint (Carrim, 2012). Thus, the traditional Indian family can be described as a 'social unit with two or three generations of paternally related males and their dependents who share a common residence, eating facilities, and more important, property' (Valk \& Srinivasan, 2011, p. 43). Being part of an extended family presents both benefits and challenges for employed women. Extended family members assist with tasks in the home domain; in particular, they assist employed women by taking care of their children (Rao, Apte \& Subbakrishna 2003; Tengimfene, 2009). However, being part of such a family places an additional responsibility on Indian women as they are held responsible for the caretaking of elderly family members (Velgach \& Rajadhyaksha, 2009), and extended family members play a great role in enforcing gender appropriate roles and behaviours (Carrim, 2012). The traditional Indian culture also encourages patriarchy within the family unit (Banerjee, 2008; Carrim, 2012, 2015). Patriarchal ideologies lay emphasis on the traditional roles of the wife being responsible for the home domain and the husband for the work domain (Jeftha, 2006). The employment of males in a patriarchal society is essential as money signifies power, allows them control over women and ultimately impacts on their masculinity (Ichou, 2008; Sedumedi, 2009). In such a society, women have a minimal say in decision-making (Bhattacharyya \& Korinek, 2007) and approval from the husband is required to pursue a career (Gupta \& Sharma, 2002).

However, the roles of Indian women are changing to include an occupational identity (Valk \& Srinivasan, 2011). This transformation can be attributed to the concept of 'cultural hybridity' where traditional meanings are shed and new symbolic expressions are shaped through the process of 'cultural borrowing' (Steger, 2009). This change occurs at the individual level (i.e. values, viewpoints and identities) as well as at the group level (i.e. social and cultural systems) (Berry, 2003). However, even though the roles of Indian women are changing, they are not emancipated from their traditional roles and thus find it challenging to fulfil both their domestic and professional roles (Carrim, 2012). In addition, research executed by Salway et al. (2005) indicated that husbands were the authority figures and breadwinners in their homes, even though their wives were employed and contributed to the household. The men explained that women being employed challenges the traditional gender roles and thus gives rise to anxiety. Thus, it is no surprise that many Indian women would place their domestic roles above that of their careers (Patel \& Parmentier, 2005).
Research conducted by Panda (2010) revealed that spousal violence intensified due to the empowerment of Indian women, which clashed with traditional values and expectations. Similarly, the study carried out by Barkhuizen and Pretorius (2005) revealed that South African professional women were emotionally abused by their partners as a result of their career success. However, extant research also revealed that the financial independence of women shields them from domestic violence, as researchers argue that egalitarian relationships are formed from such situations, which affords women with the confidence to leave their abusive partners (Salway et al., 2005). Researchers such as Ruddick (2007) and Studer (2007) indicated that the financial independence of women also enhances their decision-making power. Other researchers contended this notion by declaring that even in marriages perceived as egalitarian or in those where the wives' income is higher than the husbands', the final decision for important matters rests with the husband (Bartley, Blanton \& Gilliard, 2005; Tichenor, 2005). Similarly, it is virtually impossible for an Indian woman to pursue a career without (at least) the husband's consent (Gupta \& Sharma, 2002). These mixed results can be explained by Mujumdar (2008) who states that authority in the marriage is determined by the couple and the way in which the husband perceives his wife's employment.

Previous research revealed that many Indian women would not be comfortable with their husbands undertaking work in the home realm (Patel \& Parmentier, 2005). However, the study carried out by Panda (2010) in India showed that most of the female participants in dual-career relationships acknowledged their spouses' roles in the domestic domain. Extant research also revealed that extended family members experience difficulty in accepting these new gender roles as they continue to expect Indian women to maintain the traditional domestic roles and this is a major cause of stress for Indian professional women (Narayan \& Bhardwaj, 2005; Velgach \& Rajadhyaksha, 2009). In addition, the careers of Indian males take precedence over their wives' careers, regardless of her occupational status, as Indian women are tradition bound (Carrim, 2012). As a result, Indian women face unique cultural barriers as the age and gender hierarchy has to be accommodated in their homes, restrictions are placed on their professional travel and family obligations take priority over career advancement (Gupta \& Sharma, 2002). Thus, Indian women who have reached high career levels are viewed as directly confronting the challenges, relying on the family support and personal drive to succeed (Nath, 2000).

\section{Spousal support amongst dual-career couples}

Two main types of spousal support have been identified by researchers, namely emotional and instrumental support (Valk \& Srinivasan, 2011; Xu \& Burleson, 2001). Emotional support includes guidance, empathy and moral support for the spouse's career endeavours while instrumental support entails physical assistance with the day-to-day domestic tasks and childcare activities (Janning, 2006; Valk \& Srinivasan, 2011). Research revealed that women value 
emotional support, as instrumental support can be bought (Ezzedeen \& Ritchey, 2008).

The study conducted by Gordon and Whelan-Berry (2004) in the USA assessed four support roles that the partners of professional women are involved in, which include: interpersonal support, financial assistance, career management support and assistance with home and family tasks. Also in the American context, Ezzedeen and Ritchey (2008) proposed a typology of six support behaviours depicted by the husbands of managerial women that include: career assistance, esteem support, assistance with family members, emotional support, assistance with household activities and the husband's career and lifestyle choices. Research conducted by Välimäki et al. (2009) in Finland resulted in spousal support being categorised across a continuum from supportive to non-supportive. Thus, it can be seen that various spousal support behaviours have been investigated in the American and Finnish contexts, with emotional and instrumental support being the overarching types of spousal support.

The spouse has been dubbed an essential source of support in dual-earner families, even though support may be received from other avenues (Ezzedeen \& Ritchey, 2008; Gordon \& Whelan-Berry, 2005). Spousal support is essential as husbands provide stability in the home domain and alleviate the conflict between work and family life (Rao et al., 2003). Although it has been revealed that social support enhances professional success (Friedman \& Greenhaus, 2000), there is a greater need for spousal support due to the increased presence of nuclear families and consequently the decrease in support systems (Narayan \& Bhardwaj, 2005). In addition, the need for spousal support is heightened for women who belong to cultures characterised by low levels of gender egalitarianism (Rosenbaum \& Cohen, 1999) as they adopt stereotyped gender roles and believe that parental and marital relationships weaken as a result of them being employed (Emmons, Biernat, Tiedje, Lang \& Wortman, 1990). As other sources of support do not provide sufficient psychological compensation (Xu \& Burleson, 2001), the husband is regarded as the closest person to a married professional woman and the one who understands her situation (Noor, 2002). Husbands therefore have a vital role to play as they fill the void experienced by their wives.

It is also evident that spouses have a substantial impact on their wives' career decisions (Rastogi \& Bansal, 2012; Välimäki et al., 2009). However, there is limited research available on the degree of impact that spouses have on their wives' career progression, with the available research producing mixed results. Many researchers have highlighted the supportive role that husbands play, which results in the acceleration of their wives' career advancement (Ruddick, 2007; Ruth, 2009; Tharenou, 2001). Researchers also indicated that unsupportive husbands are unable to cope with their wives' successes and thus serve as an obstruction to their career progression (Lämsä \& Hiillos, 2008; Tengimfene, 2009).
In addition, the study conducted by Sedumedi (2009) revealed that African men require their wives to adopt the socially constructed domestic roles regardless of their employment, which results in the women declining career opportunities as they anticipate that their husbands would be unsupportive and disapproving. Similarly, Rao et al. (2003) indicated that having an unsupportive husband would result in professional Indian women leaving the work arena. Thus, it is no surprise that the lack of spousal support is one of the main factors that thwarts the career advancement of women (Rastogi \& Bansal, 2012).

\section{Research design Research approach}

Due to the subjective nature of the topic and the limited research available on the subject, both globally and in South Africa, a qualitative approach was chosen. Qualitative research is also effective in constructing a better understanding of variables that are difficult to quantify, such as attitudes, political opinions or religious beliefs (Deeptee \& Roshan, 2008). Thus, the qualitative approach was selected in order to gain in-depth information regarding the support offered by Indian husbands to their wives in executive positions, to understand the underlying reasons for the perceptions being held and to ascertain the impact that spousal support has on a woman's career advancement.

\section{Research strategy}

In-depth, life-story interviews were conducted with nine Indian female managers in dual-career marriages. This strategy was adopted in order to gain a better understanding of the various factors that shape the perceptions that Indian female executives currently hold with regard to the spousal support they receive in their career advancement.

\section{Research method}

\section{Research setting}

Face-to-face interviews were conducted at a convenient and comfortable location for the participants. In most cases, the participants' homes were used to conduct the interviews. In cases where participants were afraid that their husbands, or other family members, would eavesdrop on what they were saying, one of the researcher's home was used as a venue for the interview.

\section{Entrée and establishing researcher roles}

The key informants for this study were employees occupying lower level positions in the respective companies where the participants were employed. These employees provided the contact details of Indian female managers who were potential participants for this study. The managers were contacted via email or telephone and a meeting was then scheduled with participants who met the criteria for inclusion in the study and who were willing to participate, at a suitable time and venue. 


\section{Sampling}

Ablend of purposive and snowball, non-probability sampling methods were used to obtain participants for the study. Purposive sampling is a strategy that is used to select individuals who will provide the most information about the subject being examined, to participate in a study (Barbour, 2008; Leedy \& Omrod, 2010). In this study, purpose sampling was used to identify female managers who met the following predetermined criteria:

- The participants had to occupy a managerial position so that we could explore the pressures ensuing from both personal and professional domains as a result of their career progression.

- The participants had to be Indian so that the cultural context could be investigated and the unique challenges faced by this minority group could be understood.

- The participants had to be married and in dual-career relationships, as this criterion requires commitment to the spouse and/or the family in addition to work obligations.

Snowball sampling was also used in which participants were informants and recommended potential participants for the study (Sommer \& Sommer, 2002; Welman, Kruger \& Mitchell, 2005). This sampling method was employed as it was difficult to identify participants who met the requirements for the study. The final sample consisted of nine female managers. Table 1 provides the biographical summary of the participants.

\section{Data collection}

Data were collected using in-depth, semi-structured interviews as this method is beneficial in gaining insight into the actions of individuals and pursuing fresh perspectives of the phenomena under study (Robson, 2002). The interviews focused on the cultural background of participants, their personal history as well as their viewpoints on various aspects related to the topic. In-depth interviews were deemed the most suitable method to obtain sensitive information regarding the participants' personal and professional lives (Barbour, 2008).

Open-ended questions were asked during the interview to allow participants to respond freely and for the discussion to focus on issues of greatest significance to them (Barbour, 2008). This allowed for a complex and comprehensive understanding of perceptions regarding the spousal support received by Indian female executives.

\begin{tabular}{|c|c|c|c|c|}
\hline Pseudonym & Age range & Children & $\begin{array}{l}\text { Job level relative } \\
\text { to spouse }\end{array}$ & $\begin{array}{l}\text { Earnings relative } \\
\text { to spouse }\end{array}$ \\
\hline Wife 1 & $25-34$ & Yes & Higher & Similar \\
\hline Wife 2 & $45-54$ & Yes & Higher & Similar \\
\hline Wife 3 & $35-44$ & Yes & Equal & Lower \\
\hline Wife 4 & $45-54$ & Yes & Higher & Higher \\
\hline Wife 5 & $25-34$ & Yes & Higher & Lower \\
\hline Wife 6 & $35-44$ & Yes & Equal & Higher \\
\hline Wife 7 & $45-54$ & Yes & Higher & Similar \\
\hline Wife 8 & $25-34$ & Yes & Higher & Not aware \\
\hline Wife 9 & $45-54$ & Yes & Higher & Higher \\
\hline
\end{tabular}

An interview guide was used and the questions were asked in a methodical manner through the use of a semi-structured interview format. This allowed the researchers to probe when unclear responses were given (Rubin \& Rubin, 2005). Specifically, life-story interviews were used, with questions that focused on the participants' childhood, their societal and cultural background, as well as the dynamics transpiring in their current work, marital and family life. By relating their life stories, participants try to understand reality in terms of the meaning such stories add to their self-concepts and their lives in general (Shamir \& Eilam, 2005). Life-story interviews were conducted to accurately understand the participants' perceptions, as various historical factors and experiences shape individuals and mould their perceptions.

Prior to the main interviews, two pilot interviews were conducted with females who met the predetermined criteria. After the interviews were conducted, participants were questioned about their experience of the interview process, unclear questions and those that did not elicit the required information were amended, and the interview schedule was modified.

\section{Recording of the data}

Recording of the interviews was performed through the use of a digital voice recorder once permission was obtained from the participants to do so. The interviews were then transcribed verbatim for further analysis. An additional recording device was used as a backup in case any technical difficulties arose. An interview feedback form was used to document field notes, which included the body language of interviewees, reflective notes, contextual information about the interview and in certain cases, important information revealed by the interviewees after the recorder had been turned off. Permission to use information after the recorder was switched off was obtained from participants. The participants agreed that the information could be used, provided the information did not identify them.

\section{Data analysis}

Thematic content analysis was used to analyse the verbatim transcripts of the interviews conducted and the field notes documented in order to gain a better understanding of the responses and to make sense of the data. The data analysis process as indicated by Creswell (2009) was followed. The data were 'cleaned' to ensure that it was error-free, complete and did not contain any information that could lead to the identification of participants (Saunders, Lewis \& Thornhill, 2009). After methodically working through the data, preliminary codes were generated. Atlas.ti was then used to group the codes into families and networks to depict common themes that emerged in the context of the data. The themes were then peer-reviewed and presented to the participants in order to refine the themes until they were deemed suitable.

\section{Strategies employed to ensure quality data}

Triangulation of the data was done to construct a comprehensible justification for the themes that emerged. 
This was done through discussions with individuals who were well informed about the Indian culture. Discussions related to the topic were followed on a Facebook group named Ask Chaachi Ma Fans (ACMF), which comprised 12400 individuals, with the majority of followers being South African Indians. Further insight and understanding of the participants' perceptions was obtained through these means. The researchers also used various communication techniques, as suggested by De Vos, Strydom, Fouché and Delport (2005), such as probing, paraphrasing, summarising, clarifying and reflecting, to ensure that they accurately interpreted the information being conveyed.

The entire project was reviewed by an independent, qualitative researcher to ensure an objective evaluation of the study's outcomes. In order to validate the information provided, member checks were conducted, as recommended by Cresswell (2009). In addition, detailed descriptions of the participants and the associated contexts were provided to enhance transferability (Maree, 2010). Furthermore, an 'audit' approach was adopted in order to enhance the dependability of the research (Lincoln \& Guba, 1985). Records were kept of the communication with participants, research meetings, interview transcripts, field notes, interview recordings, personal memos and data analysis decisions, and these were stored electronically.

\section{Reporting}

The research findings are discussed in the subsequent section and follow a reporting style that is objective. The main themes and subthemes are discussed, which are substantiated by verbatim excerpts from the data and existing theory. In order to ensure the confidentiality of the information obtained, all identifying information was removed from the transcripts and pseudonyms were assigned to the participants.

\section{Findings}

The findings focus on the pertinent socio-cultural and marital dynamics that have shaped the women's perceptions regarding the spousal support they receive in their career progression.

\section{Shifting roles of Indian women}

Most participants concurred that the traditional Indian culture prescribed compartmentalised roles for men and women. Specifically, women were required to adopt the role of being housewives, while men ought to be the breadwinners of the home. Wife 4 highlights the role that women fulfilled in traditional Indian homes:

'They did all the cooking and cleaning. They were domesticated women, they didn't do anything else.' [Wife 4, medical manager, 52 years old]

Over time, changes in these traditional roles were seen as Indian women began educating themselves and ventured into the working world. However, many educated Indian women did not pursue careers as a result of a personal choice, as decreed by their spouse, or as instructed by extended family members. Wife 5 recalls family members who left the working arena as their husbands instructed them to do so:

'I had aunts who were teachers and they stopped teaching. I had an aunt who was a doctor and she stopped because her husband wanted her to stay at home.' [Wife 5, tax manager, 32 years old]

Wife 1 describes the influence that extended family members, particularly the wives' in-laws, can have on an Indian woman's decision to pursue a career:

'I can think of a friend that dropped out of working. She was a qualified lawyer but she married into a very orthodox family, so she stopped.' [Wife 1, medical manager, 33 years old]

However, the participants' families encouraged them to pursue careers which were not limited in scope. Thus, the shift from women being housewives to being professionals was apparent. Female participants also stated that a career in a male-dominated field was acceptable, as Wife 1 indicates:

'I was never ever told that I can't do anything or that certain jobs are not for women. If I wanted to be a pilot, I could have done that.' [Wife 1, medical manager, 33 years old]

Participants highlighted that the transformation also included careers taking precedence over traditional gender roles amongst women in the current Indian society, as Wife 1 explains:

'There's definitely a trend towards the independent woman and the career woman. Women are even getting married later these days because they are establishing their careers.' [Wife 1, medical manager, 33 years old]

This transformation has been attributed to the rising cost of living and the heightened need for independence. Black economic empowerment also contributed to this revolution as it provides further opportunities for Indian women to advance than those that existed in the past. However, participants indicated that even though this transformation occurred and a division of labour exists in their households, women are still held primarily responsible for domestic tasks which include child rearing, cooking and managing the home. This situation is described by Wife 6:

'At the end of the day no matter what you do, no matter what your level is in the workplace, there are certain responsibilities at home that are primarily yours.' [Wife 6, legal manager, 43 years old]

\section{The challenges experienced by Indian women and the reasons why they work}

The greatest challenge experienced by Indian women is the balancing of work and family demands. Specifically, the participants noted the occurrence of a negative spill over between work and family life, as Wife 8 describes:

'Although people say work stays at work and home stays at home, as humans it's completely impossible to do that. You come home and you still thinking of this problem that you trying to sort out at work. As a mother you worry about your kids 
especially if they are not well or they've got an appointment, they've got projects or something. As a wife you worry about your spouse.' [Wife 8 , financial manager, 34 years old]

In addition, the participants identified the limited time that they have as a major challenge as they are unable to distribute the time equally between their professions, spouses and children, and having time to attend to their personal needs. This resulted in feelings of guilt brewing amongst Indian professional women, which was heightened when they had to embark on work-related travel and spend greater hours away from the home. Guilt also arose as certain family or community members, who accepted the traditionally defined gender roles, criticised Indian professional women for pursuing careers, as Wife 5 explains:

'Many of my mother's sisters think that I am doing something wrong by going out and working. I get a lot of comments from friends and family that I should actually be at home and looking after my son because he is more important.' [Wife 5, tax manager, 32 years old]

Regardless of the challenges experienced, the two main reasons why the women were employed were to satisfy a personal need, as well as to fulfil a financial need. The women highlighted that being involved in careers provided them with independence due to the earning power that a career affords and fulfilled their need for personal growth as they classified their work as being challenging and intellectually stimulating. Participants also indicated that working women are respected in the Indian community. Wife 3 explains how her employment earned her respect from her spouse and family members:

'It's a typical Indian thing where once a woman starts working the whole family respects you more. When I was at home I started feeling like I'm not part of the outside world and then the family members who worked would all be talking and I don't contribute because I don't know. Respect came from him and from the entire family and now when anyone comes over I can have a conversation with them.' [Wife 3, medical technologist manager, 42 years old]

Wife 9 pointed out the importance of her career, as it allows her to interact with other adults, which serves as replacement for the lack of communication with her spouse:

'There's that kind of communication that I have with the other adults that really stimulates me. I think there's an underlying need because there's no stimulation from a partner at home that I can talk to or discuss with.' [Wife 9, medical manager, 53 years old]

\section{Women's perceptions of support received from the spouses}

Two participants indicated that their husbands were unsupportive of their career advancement, while the remaining seven participants classified their husbands as supportive due to the physical and emotional support that they offer. Physical support includes domestic duties such as cooking and child rearing. Wife 1 provides a description of the physical support offered by her husband:
'He told me once a week if I just need a break from work and from the house then he'll come home early and take over. I can then go for yoga or just meet my friends for a cup of coffee if I want to.' [Wife 1, medical manager, 33 years old]

Emotional support comprises the motivation, understanding and advice required by the women to manage their workrelated distresses, career decisions and educational choices. Wife 6 explains the emotional support received from her husband when pursuing an educational opportunity:

'He feels that I should always advance my studies so he encourages me and says "Look it can only be good for you, go ahead and do it".' [Wife 6, legal manager, 43 years old]

The women highlighted the significance of emotional support received by husbands, as expressed by Wife 2:

'I rely on my husband emotionally a lot because I really just want him to say "It's okay if you can't do it all".' [Wife 2, human resource manager, 50 years old]

The participants, who classified their husbands as unsupportive, indicated that they did not receive financial, physical or emotional support from their spouses. This resulted in them bearing an overload of tasks as their responsibilities lie in both the home and work domains. Wife 4 compares her situation to that of being a single parent:

'It's very difficult to play all the roles. I have to help out with the children's homework, their emotional needs, and whatever they need I have to sort it out. Then my own personal things after they go to bed at night, then I sort out my work issues. So it's very difficult. It's almost like being a single parent.' [Wife 4, medical manager, 52 years old]

The roles adopted by the participants' parents had a significant impact on the manner in which participants evaluated the behaviour of their husbands and their perceptions regarding women's career advancement. Wife 4 illustrates this as she compares her husband as a nonprovider to her father who was a breadwinner:

'My dad was a sole provider and he provided very well. It just came across that the man should be the provider. I never even had a second thought that a man won't provide.' [Wife 4, medical manager, 52 years old]

Wife 7 explains that her husband's perceptions regarding women's career advancement were shaped by the roles adopted by the women in his family:

'My husband understands that I'm not the typical housewife. His family background is different as his mother was educated. She was a smart woman and she ran three or four businesses successfully.' [Wife 7, financial manager, 54 years old]

All participants iterated the importance of spousal support for their career advancement. Emotional support provided the women with the necessary impetus to advance, while physical support allowed the women to focus on workrelated tasks. Wife 8 states the impact that her husband's support had on her career advancement: 
'I don't think I would have advanced without his support. Especially if I had a husband who didn't help me with the kids, it would have been very difficult. I don't think I would have had the guts to try things or apply for courses and do things differently.' [Wife 8, financial manager, 34 years old]

The participants, who classified their husbands as unsupportive, highlighted the negative effects that such circumstances had on their careers, as Wife 9 explains:

'I think I would have been further in my career life. I had to limit it because of my home situation. I was a very career-orientated, academic type of person. I think I would have been a professor.' [Wife 9, medical manager, 53 years old]

Thus, the participants agreed that the choice of spouse is crucial for the career progression of women. The words of Wife 9 mirror that of the majority of participants:

'My advice would be that if women want to pursue careers, they must think twice about who they marry. If you are a professional, you should marry somebody that is also a professional.' [Wife 9, medical manager, 53 years old]

\section{Marital and family dynamics}

Marriage is held in high esteem in the Indian culture and is deemed to be blessed when the parents choose or approve of the spouse for their child. Wife 7 describes how she was rejected by her family because they did not approve of the person she chose to marry:

'My parents were not in favour of me getting married to my husband so when I turned twenty-one I walked out of the house and got married. When I left home, I lost a lot of respect in the community and people actually looked down upon me. My family didn't have anything to do with me for almost twentytwo years.' [Wife 7, financial manager, 54 years old]

The majority of participants regarded their families to be nuclear. However, most of them had an extended family member for whom they were responsible and either resided with them or lived nearby. Many participants indicated that such a situation results in an additional responsibility being placed on their shoulders, as Wife 8 explains:

'My mother-in-law came to stay with us about three years ago. That was a challenge because we were independent and then she came in. She's old and she's not very well so in terms of that it is a challenge.' [Wife 8 , financial manager, 34 years old]

However, participants also mentioned the benefits of having extended family members present as Wife 3 explains:

'My mother-in-law lives next door. It's a big positive to know that she's around and that she'll check up on the maid and on my son.' [Wife 3, medical technologist manager, 42 years old]

Amongst most of the couples, the wives reached a higher education level than their husbands. In certain cases, the level of education of spouses relative to one another had a positive effect on their marital relationships, as it encouraged the husbands to advance academically. However, in other cases it impacted negatively on the way the spouses perceived each other, as Wife 9 describes:

'He never studied and he never achieved anything. He's a nothing.' [Wife 9, medical manager, 53 years old]

In terms of their careers, the women excelled in their respective fields, with many having received awards and prestigious nominations. The majority of wives also occupied a higher career position than their husbands, as depicted by Wife 4:

'I moved up faster than him. Now eventually he's in sort of a managerial position but I've been there for the past ten years.' [Wife 4, medical manager, 52 years old]

The majority of the women reported that their husbands viewed their career successes in a positive light, with reports of the husbands being happy and proud of their wives. However, two women indicated that they faced negative repercussions from their husbands as a result of their career progression. The women indicated that their career advancement resulted in a power struggle ensuing in their marriages, which led to them being verbally and/or physically abused by their husbands. Wife 9 describes such a situation:

'He's definitely got an inferiority complex and that is why he tries to use violence as the only mechanism to show his power. When he's abusive, he'll scream and say: "Go and bring your

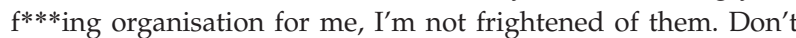
think you're this big person in the organisation." In that way it comes out.' [Wife 9, medical manager, 53 years old]

In terms of the income levels of the couples, three women earned approximately the same as their spouses, two wives earned less than their husbands, three wives earned more than their husbands and one participant was unsure about her husband's earnings. Three participants indicated that they were the primary breadwinners in their homes and thus work to provide financial support for their families. Most participants indicated that their financial status did not affect their husbands and thus did not experience negative repercussions as a result of their earnings. However, some wives also felt that they received less support from their husbands due to their earnings. Wife 9 describes the financial responsibility that rests on her shoulders:

'He earns very little and most of what he earns he takes for himself. How would my kids survive without me?' [Wife 9, medical manager, 53 years old]

Mixed results were obtained regarding decision-making in their relationships. Most of the participants indicated that decisions were made through consultation with their husbands. However, participants mentioned that the ultimate decision-making power rests with the husbands, as Wife 2 indicates:

'I said to him that I think this is what I think we should be doing but it was really up to him in the end to say yes. If he said no, he doesn't think it's going to work then I would have just left it.' [Wife 2, human resource manager, 50 years old] 
A few women indicated that decision-making is autocratic in their homes, with the husband being responsible for making important decisions. In other instances, the decision-making responsibility primarily rests with the wives, as Wife 4 explains:

'I do consult him occasionally but he's very difficult to approach and he doesn't want to commit himself so most of the times I make the decisions on my own.' [Wife 4, medical manager, 52 years old]

As a result, the majority of the women also revealed that their husbands' careers take precedence most of the time, as Wife 5 explains:

'His career always comes first. I'm starting a new job tomorrow and he just left to go to another province yesterday. His things always come first and I just have to manage.' [Wife 5, tax manager, 32 years old]

\section{Discussion}

In alignment with Valk and Srinivasan (2011), the participants of this study indicated that a transformation from the traditional roles of women being housewives to them being career women is apparent in the contemporary Indian society. The participants highlighted the crucial role that husbands play in the wife's decision to pursue a career. Similar findings were produced by Gupta and Sharma (2002) who indicated that it is virtually impossible for an Indian woman to pursue a career without (at least) the husband's approval. Even though the transformation brought about greater acceptance and encouragement of Indian women being involved in careers, with couples perceiving their relationships to be egalitarian, equality in the distribution of tasks is not prevalent, as Indian women were still held predominantly responsible for childcare and household duties in addition to their work responsibilities. The results of this study thus contradict the assertion by Giddens (2004) that women who enter into the working arena are emancipated from their domestic duties. Such a situation did not occur amongst participants in this study or in other studies that examined collectivist cultures (Carrim, 2012; Shaik, 2003; Wafula, 2010). In addition, Coltrane (2004) declared that the attitudes towards equal distribution of tasks amongst spouses have transformed quicker than their actual behaviour. Rudick (2007) explained this occurrence with the concept of the 'traditional undercurrent' which exists even amongst couples who consider their relationships to be egalitarian. This undercurrent of traditionalism sees women as being predisposed to domestic responsibilities and, therefore, they are held responsible for the majority of this work. Thus, it appears that egalitarianism appears to be more of a perception than a reality amongst South African Indian dual-career couples.

In accordance with the findings of Narayan and Bhardwaj (2005) and Rastogi and Bansal (2012), South African Indian families have also transformed as being part of a nuclear family appears to be the norm amongst participants. However, extended families have not been completely dissolved as participants indicated that they were still responsible for an extended family member who either lived with them or nearby. In line with extant research, the current study revealed that such family arrangements pose both benefits and challenges to professional women. Similar to the studies conducted by Tengimfene (2009) and Rao et al. (2003), the current study found that extended family members assist with domestic responsibilities, especially childcare tasks. This family arrangement also places a burden on Indian women, as was found by Velgach and Rajadhyaksha (2009), as they are required to attend to the welfare of elderly family members in addition to other work and domestic responsibilities. Although Carrim (2012) found that extended family members had a great influence in enforcing gender appropriate roles and behaviours, the current study found that specifically the gender roles adopted by the husbands' and wives' parents had a significant impact on the participants' perceptions regarding women's career advancement and the support offered to wives. In addition, the current study revealed that extended family members made participants feel guilty for pursuing their careers. However, these family members did not have the authority to enforce their viewpoints regarding gender appropriate roles and behaviours. A possible explanation for this is that the dissolving of extended families to nuclear ones has resulted in the limited influence that extended family members have on Indian couples. Thus, the proclamation by Patel, Power and Bhavnagri (1996) appears to be true in that the collectivism of the Indian culture is transforming in South Africa to include Western individualism.

The predominant reasons why women work, as revealed in this study, support the findings of Olarte (2000) in that women work to satisfy financial needs, for personal fulfilment, or both. The rising cost of living was one of the main drivers for the participants to work, as participants indicated that they worked to enjoy a desired lifestyle, which was not possible on a single income. The same was found to be true in different cultural contexts as revealed by Tengimfene (2009). However, a few participants indicated that they were the primary breadwinners in their homes. This is not an unusual occurrence, as Patel et al. (2006) revealed that in many South African homes, the financial contribution of women is essential, if not the only, source of income. In addition, the findings from the current study and research conducted by Valk and Srinivasan (2011) revealed that work fulfils a personal need for women, as it affords them independence and security. Many of the women also indicated that work satisfied their need for achievement, as was revealed in the study by Mujumdar (2008). Furthermore, participants indicated that they gained respect from their spouses and other family members as a result of them being involved in careers. This aligned with the research by Schieman and Taylor (2001), which indicates that careers provide women with a feeling that they matter and give them a place in society. An interesting finding of this study was that work allowed the women to interact with other adults, which in certain cases substituted for the lack of communication with their spouses. 
The current study reveals that certain marital dynamics impacted on the perceptions regarding women's career advancement and ultimately on the support offered by the spouses. Amongst most of the couples, the wives obtained a higher education level and occupied a higher career position than their spouses. Most of the husbands responded positively to their wives' career success, although in certain marriages it was reported that the husbands felt threatened by their wives' progression. In addition, male dominance was a strong underlying thread that was apparent, as men were given greater power over important matters in the marriage. These dynamics can be attributed to the patriarchal attitudes embedded in the husbands and confirms the assertion by Banerjee (2008) that Indian families are traditionally patriarchal in nature. The findings of this study are aligned with Kehler (2001), who declared that husbands who hold patriarchal attitudes may be dissatisfied with their wives self-confidence and may be intimidated by their wives' career advancement.

The financial responsibility, amongst most of the couples in this study, was shared between the spouses and the wives were satisfied with this arrangement. However, wives who indicated that they were the primary breadwinners in their homes and earned more than their husbands feared that these dynamics would brew competitive feelings in their husbands, as was found in the study conducted by Steil and Weltman (1991). In addition, Ezzedeen and Ritchey (2008), as well as Ruddick (2007), established that gender norms do not change when the wives contribute financially, even when their contribution exceeds that of their husbands. However, a bleaker situation occurred amongst couples in this study, as some of the wives felt that their husbands were less supportive due to their earnings. They noted that a power struggle arose in their marriages, as a result of their career advancement, which led to them being physically and/or verbally abused by their husbands. This is in line with the findings by Panda (2010), which revealed that the empowerment of Indian women, combined with traditional expectations and values, led to an increase in the rate of spousal violence. Similarly, Sedumedi (2009) highlighted that black (African, Indian and coloured) employed women were more susceptible to abuse, as larger earnings of women threatens the masculinity of their partners, with some men feeling emasculated, unsettled and insecure.

However, participants also highlighted that their earnings and career status afforded them with decision-making power. Most of the women indicated that decisions were made jointly with their spouses, although some women, who earned more than their husbands, indicated that they were responsible for decision-making in their homes. Similar outcomes were obtained by Ruddick (2007) and Studer (2007), as their studies revealed that increased earnings offer an alternate source of power in negotiations. These findings are in contrast to the findings of Bhattacharyya and Korinek (2007), which revealed that Indian women have a minimal say in decision-making. However, a few women noted that regardless of their earnings or career status, decisions were made autocratically by their husbands. This aligns with the findings from Bartley et al. (2005), which revealed that men had the final say in important decisions, even when the wife's earnings were greater than the husband's, or in marriages viewed as being egalitarian. Thus, it can be seen that various decision-making strategies are adopted by Indian dual-career couples.

Family background was found to be one of the main factors impacting on the perceptions and behaviour of spouses in relation to women's career advancement. Female family members, especially the mothers, emulated the appropriate gender roles for Indian women who were accepted by the participants and their husbands. Akin to the findings by Gordon and Whelan-Berry (2004) and Janning (2006), the current study reveals that the husband is an essential source of support for married professional women. In the current study, most of the husbands were supportive of their wives' career progression, with a few husbands being classified as unsupportive, as was revealed in the study conducted by Ruth (2009). The support that the professional women receive can be classified into emotional support and physical support, with the women in the current study highlighting the great importance placed on emotional support. Ezzedeen and Ritchey (2008) explained that emotional support is valued more, as instrumental support can be bought. Regardless of the significance, both physical and emotional support received from husbands had positive effects on the career progression of the women, as emotional support provided the necessary motivation for the wives to pursue their career expectations and physical support allowed the wives to pay more attention to completing work-related tasks. Such husbands can be placed under the category of a 'supporting spouse' as put forward by Välimäki et al. (2009) who explained that such husbands provide the required practical and psychosocial support for the career advancement of their wives. Furthermore, the significant impact that the husband has on the wives' career possibilities and decisions has been established by other researchers ( $\mathrm{O}^{\prime}$ Neil \& Bilimoria, 2005; Ruddick, 2007; Tengimfene, 2009).

Wives who classified their husbands as unsupportive indicated that their spouses did not provide physical, emotional or financial support. The study conducted by Rao et al. (2003) revealed that Indian women would not continue working if their husbands were unsupportive of their career ambitions. However, this was not the case in this study, as the wives classified this non-support as a career-limiting factor and mentioned occurrences where their careers had to take a back seat due to the non-support from their spouses. Such husbands can be compared to the 'counterproductive spouse', illustrated by Välimäki et al. (2009) as an individual who has a negative attitude towards his wife's career and can be viewed as an obstruction to her career achievements. This finding confirms the notion of Rastogi and Bansal (2012), who indicated that one of the main factors impacting the career progression of Indian women is the deficiency of 
spousal support. Furthermore, these findings tie in with the spousal support theory (Kanter, 1977) which posits that marriage impacts on a woman's career more unfavourably than on a man's, as married women will be less committed to their careers than single women and thus will not advance to the same degree as single women.

\section{Conclusion}

Husbands serve as an essential source of support for Indian professional women to progress in their careers to their maximum potential. The study revealed that most Indian women receive the necessary physical and emotional support from their husbands, which assists in their career progression. However, there are instances where women do not receive spousal support and this impedes their career advancement, as women have to manage their domestic responsibilities in addition to their work tasks. Although there is a transformation from the traditional gender expectations to the acceptance and encouragement of career women, Indian women are not emancipated from domestic and childcare responsibilities, even in relationships classified as being egalitarian. Thus, Indian women are required to concurrently embrace the roles of professional, partner and parent. Various factors, such as the education and career levels of spouses, reasons for the wives working, decision-making power in the relationship and the earnings of spouses have resulted in interesting dynamics transpiring that impacts on the spousal support received by Indian women in dual-career marriages and ultimately on their career progression.

This study creates awareness to management in organisations about the marital challenges Indian professional women face in their climb up the corporate ladder. It fills a gap in knowledge, as it is one of the first studies that focuses on Indian dual-career couples in the South African context and assists in explaining the dearth of Indian women in senior and top management positions in the country. From the findings of this study, organisations can develop strategies to counter the challenges experienced by these women and ultimately capitalise on the talent that this ethnic minority group has to offer. However, a limitation of this study is that it focused solely on the wives perceptions of spousal support in the Indian cultural context. Future research can include both husbands' and wives' viewpoints and can focus on other cultural groups in South Africa so that comparisons in the results can be drawn.

\section{Acknowledgements Competing interests}

The authors declare that they have no financial or personal relationships which may have inappropriately influenced them in writing this article.

\section{Authors' contributions}

S.F.A. conducted the data analysis and the final integration of the data and wrote the introduction, literature review, research design, findings, discussion and conclusion. She submitted the final draft for language editing and made corrections based on recommendations from the language editor. N.M.H.C. provided guidelines for improving the article, reviewed the data analysis, provided feedback on the final integration of data and provided feedback on the final copy of the article.

\section{References}

Abele, A.E., \& Volmer, J. (2011). Dual-career couples: Specific challenges for work-life integration. In S. Kaiser, M. Ringlstetter, M.P. Cunha, \& D.R. Eikhof (Eds.), Creating balance? International perspectives on the work-life integration of professionals (pp. 173-189). Berlin: Springer.

Banerjee, S. (2008). Dimensions of Indian culture, core cultural values and marketing implications: An analysis. Cross Cultural Management: An International Journal, 15(4), 367-378. http://dx.doi.org/10.1108/13527600810914157

Barbour, R. (2008). Introducing qualitative research. Cornwall: Sage.

Barkhuizen, M., \& Pretorius, R. (2005). Professional women as victims of emotional abuse within marriage or cohabitating relationships: A victimological study. Acta Criminologica, 18(1), 10-20.

Bartley, S.J., Blanton, P.W., \& Gilliard, L. (2005). Husbands and wives in dual- earner marriages: Decision-making, gender role attitudes, division of household labor, and equity. Marriage and Family Review, 37(4), 69-94. http://dx.doi.org/10.1300/ J002v37n04_05

Beauregard, A. (2008). Family influences on the career life cycle. In M.F. Ozbilgin \& A. Malach-Pines (Eds.), Career choice in management and entrepreneurship: A research companion (pp. 101-126). Cheltenham, UK: Edward Elgar.

Berry, J.W. (2003). Conceptual approaches to acculturation. In K.M. Chun, P.B. Organista, \& G. Marín (Eds.), Acculturation: Advances in theory, measurement and applied research (pp. 17-37). Washington DC: American Psychological Association.

Bhattacharyya, S.K., \& Korinek, K. (2007). Opportunities and vulnerabilities of female migrants in construction work in India. Asian and Pacific Migration Journal, 16(4), 511-531. http://dx.doi.org/10.1177/011719680701600404

Bilimoria, D., Joy, S., \& Liang, X. (2008). Breaking barriers and creating inclusiveness, lessons of organizational transformation to advance women faculty in academic science and engineering. Human Resource Management, 47(3), 423-441. http:// dx.doi.org/10.1002/hrm.20225

Booysen, L., \& Nkomo, S.M. (2010). Gender role stereotypes and requisite management characteristics: The case of South Africa. Gender in Management: An International Journal, 25(4), 285-300. http://dx.doi.org/10.1108/17542 411011048164

Carrim, N.M.H. (2012). 'Who am I?' - South African Indian women managers struggle for identity: Escaping the ubiquitous cage. Doctoral dissertation. Pretoria, South Africa: University of Pretoria.

Carrim, N.M.H. (2015). Stepping out of the fish tank: Ethnic identity work of Indian parents. Journal of Family Issues, 37(16), 2368-2392.

Carrim, N.M.H., \& Nkomo, S.M. (2016). Wedding intersectionality theory and identity work in organizations: South African Indian women negotiating manageria identity. Gender, Work \& Organization, 23(3), 261-277. http://dx.doi.org/10.1111/ gwao.12121

Cohen, A., Granot-Shilovsky, L., \& Yishai, Y. (2007). The relationship between personal, role, and organizational variables and promotion to managerial positions in the Israeli educational system. Personnel Review, 36(1), 6-22. http://dx.doi. org/10.1108/00483480710716696

Coltrane, S. (2004). Elite careers and family commitment: It's (still) about gender. The Annals of the American Academy of Political and Social Science, 596(1), 214-220. http://dx.doi.org/10.1177/0002716204268776

Creswell, J.W. (2009). Research design: Qualitative, quantitative, and mixed methods approaches. Los Angeles, CA: Sage.

Davidson, M.J., \& Burke, R.J. (2012). Women in management worldwide: Progress and prospects. (2nd edn.). Farnham, England: Gower Publishing Limited.

Deeptee, P.R., \& Roshan, B. (2008). Qualitative research in organisations: A new perspective. Retrieved August 24, 2015, from http://www.nyu.edu/classes/ keefer/waoe/deeprosh1.pdf

Department of Labour. (2015). 15th CEE Annual Report, 2014-2015. Retrieved November 2, 2015 from http://www.labour.gov.za

De Vos, A.S., Strydom, H., Fouché, C.B., \& Delport, C.S.L. (2005). Research at grass roots: For the social sciences and human services professions. (3rd edn.). Pretoria: Van Schaik.

Dorio, J.M. (2009). The provision of spousal support : Antecedents, consequences, and crossover effects. Doctoral dissertation. Tampa, FL: University of South Florida.

Emmons, C.A., Biernat, M., Tiedje, L.B., Lang, E.L., \& Wortman, C.B. (1990). Stress, support and coping among women professionals with preschool children In J. Eckenrode \& S. Gore (Eds.), Stress between work and family (pp. 61-93). New York: Plenum Press.

Ezzedeen, S.R., \& Ritchey, K.G. (2008). The man behind the woman: A qualitative study of the spousal support received and valued by executive women. Journal of Family Issues, 29(9), 1107-1135. http://dx.doi.org/10.1177/0192513X08315363 
Friedman, S.D., \& Greenhaus, J.H. (2000). Work and family - Allies or enemies? New York: Oxford University Press.

Gershuny, J., \& Bittman, M. (2005). Exit, voice and suffering: Do couples adapt to changing employment patterns? Journal of Marriage and Family, 67(3), 656-665. http://dx.doi.org/10.1111/j.1741-3737.2005.00160.x

Giddens, A. (2004). Sociology. (4th edn.). Oxford: Blackwell.

Gordon, J.R., \& Whelan-Berry, K.S. (2004). It takes two to tango: An empirical study of perceived spousal/partner support for working women. Women in Management Review, 19(5), 260-273. http://dx.doi.org/10.1108/09649420410545980

Gordon, J.R., \& Whelan-Berry, K.S. (2005). Contributions to family and household activities by the husbands of midlife professional women. Journal of Family Issues, 26(7), 899-923. http://dx.doi.org/10.1177/0192513X04273590

Gupta, N., \& Sharma, A.K. (2002). Women academic scientists in India. Social Studies of Science, 32(5), 901-915. http://dx.doi.org/10.1177/030631270203200505

Hewlett, S.A., \& Rashid, R. (2011). Winning the war for talent in emerging markets: Why women are the solution. Boston, MA: Harvard Business Review Press.

Ichou, C. (2008). A study investigating the construction of unemployed men's masculinity. Master's thesis. Durban, South Africa: University of KwaZulu-Natal.

Janning, M. (2006). Put yourself in my work shoes: Variations in work-related spousal support for professional married co-workers. Journal of Family Issues, 27(1), 85109. http://dx.doi.org/10.1177/0192513X05277811

Jeftha, A. (2006). The construction of masculinity and risk-taking behaviour among adolescent boys in seven schools in the Western Cape. Master's thesis. Cape Town, South Africa: University of the Western Cape.

Kanter, R.M. (1977). Men and women of the corporation. New York: Basic Books.

Kehler, J. (2001). Women and poverty: The South African experience. Journal of International Women's Studies, 3(1), 1-16.

Lämsä, A.M., \& Hiillos, M. (2008). Career counselling for women managers at midcareer: Developing an autobiographical approach. Gender in Management: An International Journal, 23(6), 395-408. http://dx.doi.org/10.1108/17542410 810897526

Leedy, P.D., \& Omrod, J.E. (2010). Practical research planning and design. (9th edn.) Upper Saddle River, NJ: Pearson Education.

Lincoln, Y.S., \& Guba, E.G. (1985). Naturalistic inquiry. Beverly Hills, CA: Sage.

Luk, D.M., \& Schaffer, M. (2005). Work and family domain stressors and support: Within- and cross-domain influences on work-family conflict. Journal of Occupational and Organisational Psychology, 78(4), 489-508. http://dx.doi. org/10.1348/096317905X26741

Maree, K. (2010). First steps in research. (4th edn.). Hatfield: Van Schaik.

Mavin, S. (2000). Approaches to careers in management: Why UK organisations should consider gender. Career Development International, 5(1), 13-20. http:// dx.doi.org/10.1108/13620430010309323

Mujumdar, S. (2008). Work stress in Australian professionals: The role of culture, gender and work-family conflicts. Doctoral dissertation. Adelaide, Australia: University of Adelaide.

Namayandeh, H., Yaacob, S.N., \& Juhari, R. (2010). The influences of work support and family support on work-family conflict (W-FC) among married female nurses in Shiraz-Iran. Journal of American Science, 6(12), 534-540.

Narayan, A., \& Bhardwaj, G. (2005). Dual career nuclear families in India: Attitudes and social support. Indian Journal of Industrial Relations, 41(1), 79-93.

Nath, G. (2000). Gently shattering the glass ceiling: Experiences of Indian women managers. Women in Management Review, 15(1), 44-52. http://dx.doi.org/10. 1108/09649420010310191

Noor, N.M. (2002). The moderating effect of spouse support on the relationship between work variables and women's work-family conflict. Psychologia: An International Journal of Psychology in the Orient, 45(1), 12-23. http://dx.doi.org/ $10.2117 /$ psysoc. 2002.12

Olarte, S.W. (2000). The female professional: Parenting, career, choices and compromises. The American Journal of Psychoanalysis, 60(3), 293-306. http:// dx.doi.org/10.1023/A:1001929922264

O'Neil, D.A., \& Bilimoria, D. (2005). Women's career development phases: Idealism, endurance, and reinvention. Career Development International, 10(3), 168-189. http://dx.doi.org/10.1108/13620430510598300

Panda, U.K. (2010). Career, conflict and attitude change and continuity. International Research Journal, 1(5), 54-57.

Patel, C.J., Govender, V., Paruk, Z., \& Ramgoon, S. (2006). Working mothers: Familywork conflict, job performance and family/work variables. SA Journal of Industria Psychology, 32(2), 39-45. http://dx.doi.org/10.4102/sajip.v32i2.238

Patel, N., Power, T.G., \& Bhavnagri, N.P. (1996). Socialisation values and practices of Indian immigrant parents: Correlates of modernity and acculturation. Child Development, 67(2), 302-313. http://dx.doi.org/10.2307/1131815

Patel, R., \& Parmentier, M.J.C. (2005). The persistence of traditional gender roles in the information technology sector. A study of Indian female engineers in India. Information Technologies and International Development, 2(3), 29-46. http:// dx.doi.org/10.1162/1544752054782457

Rajadhyaksha, U., \& Bhatnagar, D. (2000). Life role salience: A study of dual-caree couples in the Indian context. Human Relations, 53(4), 489-511. http://dx.doi. org/10.1177/0018726700534002

Rao, K., Apte, M., \& Subbakrishna, D.K. (2003). Coping and subjective wellbeing in women with multiple roles. International Journal of Social Psychiatry, 49(3), 175184. http://dx.doi.org/10.1177/00207640030493003
Rastogi, M., \& Bansal, R. (2012). What is the priority of today's Indian women professionals? Career or family: A study of decisions on work life balance. professionals? Career or family: A study of decisions on work life balance.
International Journal of Research in Economics and Social Sciences, 2(2), 176-187.

Reitman, F., \& Schneer, J.A. (2008). Enabling the new careers of the 21st century. Organization Management Journal, 5(1), 17-28. http://dx.doi.org/10.1057/ omj.2008.4

Robson, C. (2002). Real world research: A resource for social scientists and practitionerresearchers. (2nd edn.). Oxford: Blackwell Publishers.

Rosenbaum, M., \& Cohen, E. (1999). Equalitarian marriages, spousal support resourcefulness, and psychological distress among Israeli working women. Journal of Vocational Behavior, 54(1), 102-113. http://dx.doi.org/10.1006/jvbe.1998 1644

Rubin, H., \& Rubin, I. (2005). Qualitative interviewing: The art of hearing data. London: Sage.

Ruddick, L. (2007). Women: Their husbands, their careers and their families. Master's thesis. Manhattan, NY: Kansas State University.

Ruth, G. (2009). Women in senior management positions: An exploration of how they balance their role. Master's thesis. Durban, South Africa: University of KwaZuluNatal.

Salway, S., Jesmin, S., \& Rahman, S. (2005). Women's employment in urban Bangladesh: A challenge to gender identity? Development and Change, 36(2) 317-349. http://dx.doi.org/10.1111/j.0012-155X.2005.00413.x

Saunders, M., Lewis, P., \& Thornhill, A. (2009). Research methods for business students. (5th edn.). Essex: Pearson Education.

Scheener, J.A., \& Reitman, F. (2002). Managerial life without a wife: Family structure and managerial career success. Journal of Business Ethics, 37(1), 25-38. http:// dx.doi.org/10.1023/A:1014773917084

Schieman, S., \& Taylor, J. (2001). Status, roles, and the sense of mattering. Sociological Perspectives, 44(4), 471-484. http://dx.doi.org/10.2307/1389654

Sedumedi, P. (2009). A qualitative study exploring black women's perceptions of the impact of women's changing socio-economic status on intimate heterosexud relationships. Master's thesis. Durban, South Africa: University of KwaZulu-Natal.

Shaik, F. (2003). The impact of inter-role conflict on Indian women's job satisfaction and life satisfaction. Master's thesis. Johannesburg, South Africa: University of the Witwatersrand.

Shamir, B., \& Eilam, G. (2005). What's your story? A life-stories approach to authentic leadership development. Leadership Quarterly, 16(3), 395-417. http://dx.doi. org/10.1016/j.leaqua.2005.03.005

Shivani, S., Mukherjee, S.K., \& Sharan, R. (2006). Socio-cultural influences on Indian entrepreneurs: The need for appropriate structural interventions. Journal of Asian Economics, 17(1), 5-13. http://dx.doi.org/10.1016/j.asieco.2006.01.002

Sommer, R., \& Sommer, B. (2002). A practical guide to behavioral research: Tools and techniques. (5th edn.). Oxford: Oxford University Press.

Sonpar, S., \& Kapur, R. (2001). Non-conventional indicators: Gender disparities under structural reform. Economic and Political Weekly, 36(1), 66-78.

Steger, M. (2009). Global culture: Sameness or difference? In S. Eitzen \& M. Zinn (Eds.), Globalization: The transformation of social worlds. (2nd edn., pp. 147150). Belmont: Wadsworth Cengage Learning.

Steil, J.M., \& Weltman, K. (1991). Marital inequality: The importance of resources, personal attributes, and social norms on career valuing and the allocation of domestic responsibilities. Sex Roles, 24(3-4), 161-179. http://dx.doi.org/10.1007/ BF00288889

Studer, M. (2007). Negotiating the labor of love: How resources, time, and gender shape parenting agreements. Pepperdine Law Review, 34(2), 417-438.

Tengimfene, N. (2009). The work-family conflict experienced by South African women of different race groups: A phenomenological study. Master's thesis. South Africa: University of South Africa.

Tharenou, P. (2001). Going up? Do traits and informal social processes predict advancing in management? Academy of Management Journal, 44(5), 1005-1117. http://dx.doi.org/10.2307/3069444

Tichenor, V. (2005). Maintaining men's dominance: Negotiating identity and powe when she earns more. Sex Roles, 53(3-4), 191-205. http://dx.doi.org/10.1007/ s11199-005-5678-2

Tlaiss, H., \& Kauser, S. (2010). Perceived organizational barriers to women's career advancement in Lebanon. Gender in Management, 25(6), 462-496. http://dx.doi. org/10.1108/17542411011069882

Valcour, P.M., \& Tolbert, P.S. (2003). Gender, family, and career in the era of boundarylessness: Determinants and effects of intra- and inter-organizational mobility. International Journal of Human Resource Management, 14(5), 768-787. http://dx.doi.org/10.1080/0958519032000080794

Välimäki, S., Lämsä, A.M., \& Hiillos, M. (2009). The spouse of the female manager: Role and influence on the woman's career. Gender in Management: An International Journal, 24(8), 596-614. http://dx.doi.org/10.1108/175424 10911004867

Valk, R., \& Srinivasan, V. (2011). Work-family balance of Indian women software professionals: A qualitative study. IIMB Management Review, 23(1), 39-50. http://dx.doi.org/10.1016/j.iimb.2010.10.010

Vangarajaloo, M. (2011). Factors influencing the willingness of South African Indian parents to consent to their daughters pursuing tertiary education and careers. Master's thesis. Pretoria, South Africa: University of Pretoria.

Velgach, S., \& Rajadhyaksha, U.A. (2009). Gender, gender role ideology and workfamily conflict in India. Retrieved March 10, 2012, from http://www. workfamilyconflict.ca/cms/documents/38/GRI_paper-AOM2009.pdf 
Wafula, A.N. (2010). Work-family conflict among women from a collectivist culture Master's thesis. Cape Town, South Africa: University of the Western Cape.

Wei, F., Ying, F., \& Liangliang, W. (2009). The stressors in professional women's workfamily conflict: A Chinese study. Canadian Social Science, 5(3), 62-67.

Welman, C., Kruger, F., \& Mitchell, B. (2005). Research methodology. (3rd edn.). Cape Town: Oxford University Press.
Whiting, R.H. (2004). Implications of work/family strategies on Chartered Accountants career status. Accountancy Working Paper Series, University of Otago. Retrieved April 9, 2012, from http://hdl.handle.net/10523/1574

$\mathrm{Xu}, \mathrm{Y}$, \& Burleson, B.R. (2001). Effects of sex, culture, and support type on perceptions of spousal social support. Human Communication Research, 27(4), 535-566. http://dx.doi.org/10.1111/j.1468-2958.2001.tb00792.x 